\title{
Studies of reversible perspective: A methodological review
}

JOHN R. PRICE, University of Western Australia, Nedlands, Western Australia

The lack of an adequate theory of reversible perspective is largely attributable to the haphazard methodology adopted by many workers in this area of research. After more than 60 years, no standard experimental procedure has evolved, and the comparison of results from different studies is difficult. Some representative experiments are reviewed in terms of the temporal, stimulus, and procedural factors involved. It is suggested that the general use of the reversal rate measure is the major single barrier to progress, and that a continuous recording method be adopted in future experimentation.

An adequate theory of reversible perspective has yet to be established, and the reason appears to be mainly methodological. Psychologists have sought to account for the reversal phenomenon since Necker (1832) first reported apparent changes in the perspective of a plan rhomboid figure, and since the beginning of this century scores of experiments have been conducted with the "Necker Cube" and similar figures. However, little has been established, except that the reversal rate for most figures tends to increase with observation time.

Most early writers (e.g., Gordon, 1903; McDougall, 1906; Titchener, 1901) assumed that reversals represented fluctuations of attention, following Necker's report that changes could be induced by shifting attention from one part of the figure to another. An essentially similar assumption is implied by some modern authors (e.g., Gregory, 1966; Vernon, 1962). However, the term "attention" is usually undefined and used only in a descriptive sense. Alternative explanations in terms of "satiation" (Köhler, 1940; Spitz, 1963; Orbach, Ehrlich, \& Heath, 1963) and learning theory (Ammons, 1954; Ammons, Ulrich, \& Ammons, 1959) have received some support, but the evidence remains equivocal. It seems, therefore, that our knowledge and understanding of the reversal process has not advanced substantially since Necker's time.

One common feature of reversible figure studies has been the choice of a dependent variable; with few exceptions this has been the number of reversals or changes per unit of time. However, time units differ widely between studies, and this, together with differences in stimulus pattern and size, viewing distance, and conditions, makes direct comparisons difficuit. Some authors provide no information about these factors; others omit details of illumination level, amount of pretest practice, and intertrial intervals. A summary of 35 selected studies is presented in Table 1.

The purpose of the present paper is to consider some of the main methodological features of reversible figure experiments conducted during this century, and to suggest possible improvements.

\section{TEMPORAL FACTORS Trial Duration}

In experiments in which the stimulus was presented continuously, reversal rate over time has been recorded for trials of $10 \mathrm{sec}$ (Cipywnyk, 1959; Eysenck, Holland, \& Trouton, 1957), $15 \sec$ (Axelrod \& Thompson, 1962; Cohen, 1959; Jones, 1955), $30 \mathrm{sec}$ (Newbigging, 1953; Spitz \& Lipman, 1962; Thetford, 1963; Ulrich \& Ammons, 1959), $60 \mathrm{sec}$ (Eysenck, Granger, \& Brengelmann, 1957; Fisichelli, 1947; Flügel, 1913; Franks \& Lindahl, 1963; Guilford \& Hunt,
1931; Jackson, 1956; Johnson, 1937; Spivack \& Levine, 1959; Tussing, 1941), $120 \mathrm{sec}$ (Donahue \& Griffitts, 1931; Hollingworth, 1939; Mull, Armstrong, \& Telfer, 1956; Porter, 1938), $10 \mathrm{~min}$ (Bruner, Postman, \& Mosteller, 1950), and 15 min (Ammons et al, 1959).

Generally, results are presented in the form of mean number of reversals per trial, although some workers have preferred alternative measures. Brown (1955) tested Ss for 10 trials of $30 \mathrm{sec}$ duration, and compared the mean total number of reversals for each S. Mull, Ord, \& Locke (1954) recorded the mean time to observe 10 reversals over 20 trials. In a study with a three-dimensional skeletal cube, Adams (1954) recorded the latency of the first reversal. Howard (1961) adopted the same method, and referred to the reversal latency as "satiation time," suggesting that the measure might prove valuable in the study of satiation processes.

An extension of the satiation time method was anticipated by Jackson (1956) and Washburn, Mallay, \& Naylor (1931). Both recorded the average duration of each of the two phases during a particular time interval, i.e., the time during which each S reported the Necker Cube in the "up" and the "down" phases. Köhler (1940) and Hochberg (1950) measured the duration of each cycle from the beginning of the initial percept to the end of the second. The average time per cycle decreased in a manner similar to the reciprocal of the reversal rate.

Price $(1967 \mathrm{a}, \mathrm{b})$ took a continuous recording of the two phases of a reversible figure, and plotted the mean duration of each occasion of the first (P1) and second (P2) phases separately. The results showed that the increasing reversal rate, or decreasing cycle duration, is attributable to a decrease in the duration of P1 over occasions. The duration of P2 remained constant. The fact that this constancy had not been reported by earlier workers is attributable to the recording methods used.

\section{Test Duration}

The duration of the testing session also varies widely. The period of continuous observation has ranged from as little as $15 \mathrm{sec}$ (Jones, 1955) to as long as $10 \mathrm{~min}$ (Bruner et al, 1950) Yet little is known about the effects of prolonged viewing upon the reversal phenomenon. Previous studies have produced equivocal results, although most workers found that the reversal rate curve leveled off after about $2 \mathrm{~min}$. There have been reports, however, of a decline in rate when viewing is continued for a relatively long period. Bruner et al (1950) found a slight decrease in the number of Schroeder Staircase alternations towards the end of $10-$ min trials. Torii (1960) reported similar results from an unpublished study of figure-ground reversals over 12-min trials.

Price (1968) found that when viewing time was extended beyond about 10 reversals (observed under continuous viewing conditions), the duration of P1 became very erratic. Over the first 10 occasions the P1 curve declined in the usual way, but in the latter stages of testing there were several sudden and marked increases in duration. The second phase remained stable throughout the experiment. The decline in reversal rate reported by Bruner et al, and by Torii, may be due to similar fluctuations of phase duration. Further investigation of the effects of prolonged observation, using a continuous recording method, are needed.

In some studies the total observation time is held constant, but trial durations differ. For example, both Bruner et al and 
Table 1

Summany of Experimental Conditions in Some Reversible Figure Studies'

\begin{tabular}{|c|c|c|c|c|c|c|c|c|c|c|}
\hline Author & Fig & $\begin{array}{l}\text { Fig } \\
\text { Size }\end{array}$ & $\begin{array}{l}\text { View. } \\
\text { Dist. }\end{array}$ & Vis. Angle & $\begin{array}{l}\text { Repe- } \\
\text { titions }\end{array}$ & $\begin{array}{l}\text { Test } \\
\text { Durat. }\end{array}$ & $\begin{array}{l}\text { Trial } \\
\text { Time }\end{array}$ & IT! & Response & $\mathbf{N}$ \\
\hline $\begin{array}{l}\text { Adams (1954) } \\
\text { Axelrod \& Thompson (1962) }\end{array}$ & $\begin{array}{l}\mathrm{SC} \\
\mathrm{NC}+\end{array}$ & $\begin{array}{l}51 / 2 \text { in. } \\
11 / 8 \text { in. }\end{array}$ & $\begin{array}{l}28 \mathrm{in} . \\
\text { NR }\end{array}$ & $11 \mathrm{deg} 12 \mathrm{~min}$ & $\begin{array}{l}\text { NR } \\
1\end{array}$ & $\begin{array}{l}\text { ST } \\
3 \text { min }\end{array}$ & $\begin{array}{l}\text { N/A } \\
15 \mathrm{sec}\end{array}$ & $\begin{array}{l}15 \mathrm{sec} \\
\mathrm{NR}\end{array}$ & $\begin{array}{l}\text { Verbal } \\
\text { NR }\end{array}$ & 4 \\
\hline Brown (1955) & Pins & $1.6 \mathrm{in.}$ & $24 \mathrm{in.}$ & $3 \operatorname{deg} 48 \mathrm{~min}$ & 10 & 4 mill & $30 \mathrm{sec}$ & $30 \mathrm{~min}$ & Key Press & 8 \\
\hline Bruner et al (1950) & SS & NR & NR & -- & 3 & 10 min & $1 \mathrm{~min}$ & NR & NR & 19 \\
\hline Cipywnyk (1959) & NC & 1 in. & 16 in. & $3 \mathrm{deg} 36 \mathrm{~min}$ & 1 & $2 \mathrm{~min}$ & $10 \mathrm{sec}$ & $10 \mathrm{~min}$ & Key Press & 12 \\
\hline Cohen (1959) & NC & $17 \mathrm{~mm}$ & $88 \mathrm{~cm}$ & $1 \operatorname{deg} 6 \mathrm{~min}$ & 1 & $3 \mathrm{~min}$ & $15 \mathrm{sec}$ & NR & Typewriter & 26 \\
\hline Donahue \& Griffitts (1931) & $\mathrm{NC}+$ & $4 \times 3$ in. & $18-24 \mathrm{in}$. & $\ldots-$ & 4 & $2 \min$ & $1 \mathrm{~min}$ & $2 \mathrm{~min}$ & Lever & 6 \\
\hline $\begin{array}{l}\text { Eysenck. Holland \& } \\
\text { Trouton (1957) }\end{array}$ & NC & $4.5 \mathrm{~cm}$ & $48 \mathrm{in}$. & $2 \mathrm{deg} 4 \mathrm{~min}$ & 6 & $2 \min$ & $10 \mathrm{sec}$ & 10 min & Key Press & 6 \\
\hline $\begin{array}{l}\text { Eysenck, Granger \& } \\
\text { Brengelmann (1957) }\end{array}$ & NC & 8 in. & $126 \mathrm{in.}$ & $3 \operatorname{deg} 36 \mathrm{~min}$ & $I$ & $1 \mathrm{~min}$ & $1 \mathrm{~min}$ & $1 \mathrm{~min}$ & Verbal & 146 \\
\hline Flugel (1913) & $\mathrm{TP}$ & $4.5 \mathrm{~cm}$ & $40 \mathrm{~cm}$ & $6 \operatorname{deg} 26 \mathrm{~min}$ & 10 & $1 \mathrm{~min}$ & $1 \mathrm{~min}$ & -- & L-way switch & 5 \\
\hline Franks \& Lindahl (1963) & NC & NR & NR & $\ldots-$ & 0 & $1 \mathrm{~min}$ & 1 min & $30 \mathrm{sec}$ & Key Press & 92 \\
\hline Glen (1940) & NC & 2 in. & 12 in. & $9 \operatorname{deg} 32 \min$ & 5 & $90 \mathrm{sec}$ & NR & NR & Continuous & 10 \\
\hline Guilford \& Braly (1931) & $W^{\prime}$ mill & $8 \frac{1}{2} \mathrm{in.}$ & $84 \mathrm{in.}$ & $5 \mathrm{deg} 48 \mathrm{~min}$ & 2 & $3 \mathrm{~min}$ & $1 \mathrm{~min}$ & $3 \mathrm{~min}$ & Continuous & NR \\
\hline Guilford \& Hunt (1931) & NC & NR & NR & -- & 90 & 3 min & $1 \mathrm{~min}$ & $2 \mathrm{~min}$ & NR & 5 \\
\hline Hollingworth (1939) & NC & NR & $15 \mathrm{ft}$ & -- & 8 & $2 \min$ & $2 \mathrm{~min}$ & -- & Key Press & 6 \\
\hline Howard (1961) & SC & $4 \mathrm{in.}$ & $40 \mathrm{in}$ & $9 \operatorname{deg} 6 \mathrm{~min}$ & 50 & ST & ST & $15 \mathrm{~min}$ & Key Press & 2.10 \\
\hline Jackson (1956) & NC & $5 \mathrm{~cm}$ & $1 \mathrm{~m}$ & $2 \operatorname{deg} 52 \mathrm{~min}$ & 1 & $1 \mathrm{~min}$ & $6 \mathrm{~min}$ & -- & Verbal & 43 \\
\hline Jones (1955) & NC & $\begin{array}{l}11 / 2 \text { in., } \\
8 \mathrm{in.}\end{array}$ & NR & -- & $2 \sec$ & $15 \mathrm{sec}$ & $15 \mathrm{sec}$ & NR & Ss count & 251 \\
\hline Mull et al (1952) & $\mathrm{NC}$ & $5 \mathrm{~cm}$ & $1 \mathrm{~m}$ & $2 \mathrm{deg} 52 \mathrm{~min}$ & 3 & $2 \min$ & NR & $1 \min$ & NR & 40 \\
\hline Mull et al (1954) & NC & 2 ill. & 36 in. & $3 \mathrm{deg} 10 \mathrm{~min}$ & 20 & $10 \mathrm{rev}$ & $10 \mathrm{rev}$ & $2 \min$ & Continuous & 30 \\
\hline Mull et al (1956) & $\mathrm{KC}$ & $2 \mathrm{itt}$ & 36 in. & $3 \mathrm{deg} 10 \mathrm{~min}$ & 3 & $2 \min$ & $2 \min$ & NR & Verbal & 30 \\
\hline Newbigging (1953) & SS+ & $21 / 2 \mathrm{in}$. & $22 \mathrm{in}$. & $6 \operatorname{deg} 29 \mathrm{~min}$ & 8 & $30 \mathrm{sec}$ & $30 \mathrm{sec}$ & $30 \mathrm{sec}$ & Key Press & 29 \\
\hline Orbach et al (1963) & NC & $21 / 2$ in. & $24 \mathrm{in}$. & $5 \mathrm{deg} 57 \mathrm{~min}$ & 2 & $1 \mathrm{~min}$ & $1 \mathrm{~min}$ & NR & $\mathrm{NR}$ & 8 \\
\hline Santos et al (1962) & NC & 2 in. & NR & -- & 144 & $2 \sec$ & $2 \sec$ & $2 \sec$ & Verbal & 20 \\
\hline Shopland \& Gregory (1964) & $\mathrm{SC}$ & $31 / 2$ in. & NR & -- & 16 & $1 \mathrm{~min}$ & $1 \mathrm{~min}$ & $10 \mathrm{sec}$ & Verbal & 12 \\
\hline Spitz (1963) & SC & 4 in. & $48 \mathrm{in.}$ & $4 \operatorname{deg} 46 \mathrm{~min}$ & $?$ & $4 \mathrm{~min}$ & $30 \mathrm{sec}$ & $2 \mathrm{~min}$ & Key Press & 138 \\
\hline Spitz (1965) & SC & $4 \mathrm{in.}$ & $48 \mathrm{in.}$ & $4 \mathrm{deg} 46 \mathrm{~min}$ & 2 & $2 \min$ & $30 \mathrm{sec}$ & $2 \min$ & Key Press & 50 \\
\hline Spitz \& Lipman (1962) & NC & 5 in. & $72 \mathrm{in.}$ & $4 \mathrm{deg} 0 \mathrm{~min}$ & 2 & $2 \mathrm{~min}$ & $30 \mathrm{sec}$ & $\begin{array}{l}30 \\
60 \mathrm{sec}\end{array}$ & Verbal & 53 \\
\hline Spivack \& Levine (1959) & $\mathrm{NC}+$ & NR & NR & -- & 1 & $1 \mathrm{~min}$ & $1 \mathrm{~min}$ & - & Verbal & 44 \\
\hline Thetford (1963) & NC & 2 in. & NR & $\ldots$ & 15 & $2 \sec$ & $2 \sec$. & $.5-8 \mathrm{sec}$ & Button & 20 \\
\hline Tussing (1941) & $\mathrm{NC}+$ & NR & $20 \mathrm{ft}$ & -- & 1 & $1 \mathrm{~min}$ & $1 \mathrm{~min}$ & -- & Ss count & 156 \\
\hline Ulrich \& Ammons (1959) & NC & NR & NR & -- & 6 & $5 \mathrm{~min}$ & $30 \mathrm{sec}$ & $24 \mathrm{~h}$ & NR & 4 \\
\hline Washburn et al (1931) & NC & $\begin{array}{l}50 \mathrm{~cm} \\
5 \mathrm{~cm} \\
5 \mathrm{~mm}\end{array}$ & $\begin{array}{l}60 \mathrm{~cm} \\
60 \mathrm{~cm} \\
60 \mathrm{~cm}\end{array}$ & $\begin{array}{r}45 \mathrm{deg} 18 \mathrm{~min} \\
4 \mathrm{deg} 46 \mathrm{~min} \\
0 \mathrm{deg} 56 \mathrm{~min}\end{array}$ & 18 & $3 \mathrm{~min}$ & $3 \mathrm{~min}$ & NR & Verbal & 12 \\
\hline
\end{tabular}

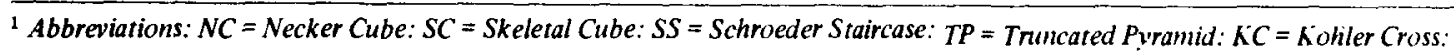
$N R=$ Not Reported $:+$ indicates that more than one stimulus pattern was used in the experiment: $S T=$ Satiation Time: $I T I=$ Intertrial Interval: $N / A=$ Not Applicable.

Ulrich \& Ammons (1959) tested Ss for a total of $30 \mathrm{~min}$ of observation. However, the former study consisted of three 10 min sessions, and the latter of six sessions of $5 \mathrm{~min}$ each. To what extent these results are comparable is unknown, but it seems that the question is worth asking. and the problem worthy of investigation.

\section{Repeated Measures}

To increase data reliability, some workers have taken repeated measures from the same Ss. Apart from experiments involving tachistoscopic presentation, the largest reported number of repetitions continued for 90 trials. each of 3 -min duration (Guilford \& Hunt, 1931). Howard (1961) recorded the mean time to the first reversal (satiation time) over 50 trials, and Mull et al (1954), the time taken to observe 10 reversals over $\mathbf{2 0}$ trials.

Together with the various number of trials. consideration must be given also to the intertrial interval (ITI). Excluding tachistoscopic studies, the range varies from $0.5 \mathrm{sec}$ (Thetford. 1963) to seven days (Donahue \& Griffitts, 1931: Price 1967b). Spitz \& Lipman (1962) retested after a lapse of from four to eight weeks, but only 24 of the original 107 Ss were nun in what appears to have been an unplanned extension of the study. Many other reports provide no indication of the time lapse between testing sessions and, accordingly, the overall influence of ITI is difficult to assess.

It appears that trial times, test durations. intertrial intervals. and number of repetitions are inextricably contounded in most of the experiments conducted to date. The problem of comparing studies is further accentuated when the results are presented in graphic form without quantitative analysis of the data.

The difficulties entailed in the use of different tims relationships could be readily overcome by the adoption of phase duration recording techniques. The method of recording used by Price provides an inexpensive. accurate. and simple solution to the problem of measurement. Ss were instructed to press a Morse key whenever the figure appeared to reverse, and to release it when the figure reverted to normil. A recording trace was offset each time the key was depressed. until the key was released. From such a record it is possible to determine, to any required degree of accuracy. the number of reversals reported during a given period, the latency of the first reversal. the duration of each occasion of each phase, and the total observation time for each phase. All of the information obtained by the recording methods described by previous workers could be derived from a continuous record of this type. 
With a duration record, the problem of trial duration can be avoided completely by plotting the mean (or median) duration of each occasion for a given number of reversals. Similarly, the question of test duration becomes much less significant since comparisons may be made in terms of time per number of reversals. Under these conditions, more precise measures are possible and a much wider range of information is provided in each experiment.

\section{STIMULUS FACTORS}

At this stage it seems worthwhile to draw a distinction between two broad types of stimuli commonly used in this area of research-reversible figures and ambiguous figures. For the purpose of this discussion, reversible figures may be defined as those having a dominant phase which is normally perceived initially, and a reversal phase which entails an apparent change in orientation of the figure (e.g., the Necker Cube and Schroeder Staircase). Ambiguous figures may be perceived initially in either of two possible configurations with about equal probability, and are exemplified by the Rubin Cross, Köhler Cross, and vase-profile figures. These two types represent two points on a continuum with respect to the degree of initial dominance of the figure. However, most experiments have involved the use of reversible figures, and the present discussion will be concerned mainly with these.

\section{Figure Size}

The most widely used stimulus pattern has been the Necker Cube, but dimensions of the stimulus have differed widely. Washburn et al (1931, p. 485) used cubes of $50 \mathrm{~cm}, 5 \mathrm{~cm}$, and $5 \mathrm{~mm}$, and reported a tendency for the small cube to fluctuate faster than the large cube. Although the finding was somewhat tentative, it appears to have been ignored by later workers in the field.

Howard (1961, Fig. 3, p. 23) found that satiation time for a rotating skeletal cube decreased with increasing retinal eccentricity. His results imply that, as the stimulus becomes more peripheral, the number of reversals per unit of time should increase. since the first reversal would occur more rapidly. From Howard's results it might be expected that, with central fixation, the relevant parts of the figure would become more peripheral with increasing angular size, and the reversal rate would therefore increase. Of course Howard's experiment is not directly comparable with that of Washburn, but it indicates that consideration should be given to figure size. In recent years, figures ranging from $17 \mathrm{~mm}$ (Cohen, 1959) to 8 in. (Eysenck, Granger, \& Brengelmann, 1957) have been used. However, the range may be wider, since many authors fail to report dimensions. For example, Tussing (1941) states only that the figure was large enough to be clearly visible from $20 \mathrm{ft}$; other writers fail to provide even that much information. The effect of figure size. therefore, is difficult to assess.

Closely related to the question of figure size is that of viewing distance, and consequently, the angular size of the figure. The wide size range of the Necker Cubes in various studies has been associated with an equal diversity of viewing distances. Glen (1940) presented a 2-in. cube at a distance of 12 in. (visual angle $=9 \mathrm{deg} 32 \mathrm{~min}$ ): Cohen $(1959)$ used a $17-\mathrm{mm}$ cube viewed from $88 \mathrm{~mm}$ (visual angle $=1 \operatorname{deg} 6 \mathrm{~min}$ ). In the Washburn study, $50-\mathrm{cm}, 5-\mathrm{cm}$, and $5-\mathrm{mm}$ cubes were presented at a distance of $60 \mathrm{~cm}$ to yield visual angles of $45 \mathrm{deg} 18 \mathrm{~min}, 4 \mathrm{deg} 46 \mathrm{~min}$, and $0 \mathrm{deg} 56 \mathrm{~min}$, respectively.

Apart from the Necker Cube, the most widely studied reversible figure appears to be the Schroeder Staircase (Bruner et al, 1950; Donahue \& Griffitts, 1931; Newbigging, 1953; Spivack \& Levine, 1959; and Tussing, 1941). Only Newbigging reported sufficient detail to permit an estimate of angular size (6 deg $30 \mathrm{~min}$ ).
Several Es used a rotating skeletal cube (Howard, 1961; Price, 1967b; Spitz, 1963, 1965). In this case, the major problem is the difference in speed of rotation of the cube. Howard and Price used speeds of $60 \mathrm{rpm}$ in a clockwise direction; Spitz used $2 \mathrm{rpm}$ in an anticlockwise direction. Price (1968) found that although direction of rotation had no significant effect on satiation time, a reduction in speed from $60 \mathrm{rpm}$ to $40 \mathrm{rpm}$ increased the satiation time by a factor of six.

\section{Illumination}

The level of illumination is seldom reported in reversiblefigure experiments, and there is no clear-cut evidence of its effect on the results. Mull, Ord, \& Locke (1954) and Mull, Armstrong, \& Telfer (1956) found no relationship between illumination and reversals of the Necker Cube and Köhler Cross, respectively, while Cipywnyk (1959) found reversal rate to be an increasing function of illumination level in a study with the Necker Cube. However, it is difficult to compare the results of even these experiments in any direct way. Mull et al (1954) recorded the mean time to observe 10 reversals over 20 trials; Cipywnyk recorded the reversal rate over six 2 -min trials. In addition, Mull et al varied both the level of lighting and the contrast by varying the power of the electric bulb and background color; Cipywnyk measured voltage drop across the bulb. Neither reported the level of illumination in photometric terms.

A similar problem applies to a number of other experiments. Usually, the stimulus figure is drawn in black ink on a white card when a plane figure is presented, but alternative methods have been employed also. Vicholshovska (1906) tested Ss with a cube made from copper wire, and although it is not stated in the report, this appears to have been a plane outline figure. Other workers (e.g., Eysenck, Holland, \& Trouton, 1957; Franks \& Lindahl, 1963) presented the figure on a transparent screen, illuminated from behind. Other studies have been conducted with overhead lighting under unspecified conditions

How these various factors affect the results of reversiblefigure studies is unknown, and there is little evidence to suggest that they have ever been seriously considered. There is an obvious need for a series of parametric studies to establish the relevant factors. Hopefully, the design of such experiments will incorporate the continuous recording method to examine satiation time, P1 duration, and P2 duration. A particular parameter might influence any or all of these.

\section{PROCEDURAL FACTORS}

Reversible figure experimentation is characterized also by a diversity of testing procedures.

\section{Viewing Conditions}

Most studies involving the use of plane reversible figures appear to have been conducted under conditions of binocular viewing. Although the majority of reports do not give the information explicitly, it is of ten implied in the instructions to Ss (when these are reported), or in the description of the experimental procedure. With other figures the reports are usually more specific. Studies with the skeletal cube by Adams (1954), Shopland \& Gregory (1964), and Spitz $(1963,1965)$ were made with monocular vision. Price (1967b) tested Ss under binocular conditions, and Dornic $(1966,1967)$, and Howard (1961) used both conditions. Axelrod \& Thompson (1962) and Brown (1955, 1962) used rotating pins stimuli and tested Ss monocularly.

Howard found that satiation time for the Howard Cube was significantly reduced under the monocular condition. This finding was confirmed by Dornić (1966) and Price (1968). Accordingly, there is room for speculation as to the possible 
effect of viewing conditions on the phase duration of plane figures. The reversal rates reported by various workers with the Necker Cube indicate that binocular satiation time for that figure would be of very brief duration compared with that of the Howard Cube. For example. graphs presented by Spitz \& Lipman (1962) show at least three reversals during the first 30 -sec trial compared with satiation times of about $60 \mathrm{sec}$ with the Howard Cube. The difference between monocular and binocular satiation times may be slight in the case of the Necker Cube. However, alternative stimuli are available for which the satiation time is likely to be long enough to allow meaningful comparison of the two viewing conditions: the Beaunis Cube figure used by Price (1967a) yielded a satiation time of $29.6 \mathrm{sec}$.

\section{Practice Effects}

With few exceptions (e.g., Spitz, 1963: Spitz \& Lipman, 1962). Es have given Ss a number of practice trials. Yet the time lapse between practice trials and the test proper is seldom reported. This suggests that the effects of practice trials were considered unimportant. However, studies with the Howard Cube have shown a $50 \%$ reduction in retest satiation time after seven days (Price, 1967b). Similarly, repeated measures within the same experimental session lead to a marked reduction in latency over successive occasions. In both cases the result must be an increase in the number of reversals reported within a given period of time. There seems no reason to expect these findings to be peculiar to the Howard Cube.

\section{Tachistoscopic Presentation}

An obvious example of the use of repeated measures is the case of tachistoscopic presentation of reversible figures. The tachistoscope offers a more rigorously controlled experimental situation than is general in this area of research, and the instrument has been widely used (e.g., Orbach et al, 1963; Santos, Farrow, \& Solley, 1962: Solley \& Long, 1958: Solley \& Santos, 1958; Thetford, 1963). The most extensive application has been made by Orbach and associates (Heath, Ehrlich, \& Orbach, 1963; Heath \& Orbach, 1963: Olson \& Orbach, 1966; Orbach, Ehrlich, \& Vainstein, 1963; Orbach \& Zucker, 1964; Orbach, Zucker, \& Olson, 1966). In a series of experiments designed to test predictions from a theory of "satiation or orientation," the Necker Cube was presented at various repetition rates and various figure-on/figure-off ratios. The maximum reversal rate of about $41 / \mathrm{min}$ was obtained at 109 exposures/min, and the minimum of no reversals was found at 46 exposures/min.

If the reversal phase is of constant duration, tachistoscopic presentation could result in the same reversal being reported on successive exposures. Under these conditions much would depend upon the instructions; if $S$ s were required to report each occasion of the reversed perspective, the reversal rate would increase markedly. Conversely, the rate could be depressed if perspective changes were reported. since at least some of these may occur between presentations (Orbach et al, 1966). However, it is not always clear from experimental reports exactly what is reported by the Ss, and more precise information is necessary if an adequate assessment of the experiments is to be made.

Another factor to be considered with tachistoscopic presentation is the effect of sudden changes of illumination Price (1967b) demonstrated "disinhibition" in the case of the Howard Cube by introducing an extraneous auditory stimulus during testing. The effect of the alien stimulus was to increase the duration of the PI during which it was introduced. Although the effect has not yet been tested with a visual stimulus, or using a plane figure, similar results might be expected. In addition, there is the more general problem of controlling extraneous noise in the experimental situation, and for that reason it is suggested that reversible figure studies should be conducted in a quiet (preferably soundproof) room.

Any increase in duration which may have occurred in previous studies would probably have passed unnoticed for two reasons. Since most of the experiments involved the Necker Cube, phase durations are likely to have been very brief. Accordingly, an increase in phase duration would be small in absolute magnitude, and have little overall effect on the results. In addition, use of the rate of reversal measure would effectively mask the effect. An increase of say $25 \%$ in the duration of a particular phase would have little apparent influence on the mean number of reversals recorded by a group of Ss during trials of $30-\mathrm{sec}$ duration. If these increases occurred at random during an experimental session, as might be expected, it would be impossible to isolate the effects of noise from those of individual differences. and other variables.

\section{Recording Methods}

Most of the recording methods are variations of the simple count of number of responses during a given period. The most common response indicator has been a key press. i.e. $S$ is instructed to press a key whenever a change occurs. and each response is recorded by an event counter (e.g. Brown. 1955: Hollingworth. 1939: Howard, 1961; Spitz. 1965). Cohen (1959) achieved the same purpose with a typewriter: Donalue \& Griffitts (1931) and Flugel (1913) used a two-way switch. or lever. Many workers, however. have depended upon the verbal report of Ss (e.g. Bills, 1931; Jackson. 1956: Johnson. 1937; Shopland \& Gregory, 1964; Spivack \& Levine. 1959: Spitz \& Lipman, 1962). Jones (1955) and Tussing (1941) simply instructed $S$ s to keep count of the number of reversals.

These recording techniques have the advantage of simplicity and economy, and are no doubt adequate for some purposes. They are also crude and wasteful of data. The reversal rate measure provides a minimum of information about individual differences. the use of such a measure increases the difficulty of making any meaningful evaluation of the results. It appears that this method of recording. more than any other single factor, is responsible for the present lack of knowledge about reversible figures.

\section{CONCLUSIONS}

There have been few attempts to control the various factors discussed above, and until this is done. the proliferation of noncomparable results is likely to continue. The inadequacy of the reversal-rate measure is indicated by the finding that the duration of the reversal phase remains constant (Price. $1967 \mathrm{a}$. b). To the extent that existing theories make no provision for the constancy, they too are inadequate.

Continuous recording offers a starting point for muchneeded methodological reform in this area by providing comparable data over a wide range of conditions. The direct comparison of satiation times could draw attention to many relevant variables. the effects of which are obscured by the reversal rate. In particular, the effect of pretest practice is readily observed in the reduction of latencies. but other factors are also likely to be relevant.

\section{REFERENCES}

ADAMS, P. A. The effect of past experience on the perspective teversal of a tridimensional figure. American Journal of Psychology, 1954,67, 708-710.

AMMONS, R. B. Experiential factors in form perception: I. Review and formulation of problems. Journal of Genetic Psychology, 1954, 84, 3-25

AMMONS, R. B., ULRICH, P., \& AMMONS. C. H. Voluntary control of perception of depth in a two-dimensional drawing. Proceedings of the Montana Academy of Science, 1959, 19, 160-168.

AXELROD, S. A., \& THOMPSON, L. On visual changes of reversible figures and auditory changes in meaning. American Journal of Psychology, 1962, 75, 673-674 
BILLS, A. G. Blocking: A new principle of mental fatigue. American Journal of Psychology, 1931, 43, 230-245.

BROWN, K. T. Rate of apparent change in a dynamic ambiguous figure as a function of observation time. American Journal of Psychology, $1955,68,358-371$.

BROWN, K. T. Complete interocular transfer of an adaptation process responsible for perceptual fluctuations with an ambiguous visual figure. Vision Research, 1962, 2, 469-475.

BRUNER, J. S., POSTMAN, L., \& MOSTELlER, F. A note on the measurement of reversals of perspective. Psychometrika, 1950, 15, 63-72.

CIPYWNYK, D. Effect of degree of illumination on rate of ambiguous figure reversal. Canadian Journal of Psychology, 1959, 13, 169-174.

COHEN, L. Rate of apparent change of a Necker Cube as a function of prior stimulation. American Journal of Psychology, 1959, 72, 327-344.

DONAHUE, W. T., \& GRIFFITTS, C. H. The influence of complexity on the fluctuations of the illusions of reversible perspective. American Journal of Psychology, 1931, 43, 613-517.

DORNIĆ, S. Reveribilita trojrorzmerných objektov. (Reversibility of three-dimensional objects.) Studia Psychologica, 1966, 8, 46-53.

DORNIĆ, $S$. Measurement of satiation in reversible figures. Studia Psychologica, 1967, 9, 18-24.

EYSENCK, H. J., GRANGER, G. W., \& BRENGELMANN, J. C. Perceptual processes and mental illness. Maudsley Monograph, No. 2 , London, Institute of Psychiatry, 1957.

EYSENCK, H. J., HOLLAND, H. C., \& TROUTON, D. S. Drugs and personality: IV. The effects of stimulant and depressive drugs on the rate of fluctuation of a reversible perspective figure. Journal of Mental Science, 1957, 103, 656-660.

FISICHELLI, V. R. Reversible perspective in Lissajous figures: Some theoretical considerations. American Journal of Psychology, 1947, 60, 240-249.

FLÜGEL, J. C. The influence of attention in illusions of reversible perspective. British Journal of Psychology, 1913, 5, 357-397.

FRANKS, C. 'M., \& LINDAHL, L. E. H. Extraversion and rate of fluctuation of the Necker Cube. Perceptual \& Motor Skills, 1963, 16, 131-137.

GLEN, J. S. Ocular movements in reversibility of perspective. Journal of General Psychology, 1940. 23. 263-281.

GORDON, K. Meaning in memory and attention. Psychological Review, $1903,10,280-283$.

GREGORY, R. L. Visual illusions. In B. M. Foss (Ed.), New horizons in psychology. Harmondsworth: Penguin, 1966. Pp. 68-96.

GUILFORD, J. P., \& BRALY, $K$, W. An experimental test of McDougall's theory of extroversion-introversion. Journal of Abnormal Social Psychology, 1931, 25, 382-389.

GUILFORD, J. P., \& HUNT, J., McV. Some further tests of McDougall's theory of introversion and extroversion. Journal of Abnormal Social Psychology, 1931, 26, 324-332.

HEATH, H., EHRLICH, D., \& ORBACH, J. Reversibility of the Necker Cube: II. Effects of various activating conditions. Perceptual \& Motor Skills, 1963, 17, 539-546.

HEATH, H., \& ORBACH. J. Reversibility of the Necker Cube: IV Responses of elderly people. Perceptual \& Motor Skills, 1963, 17, 625-626

HOCHBERG, J. E. Figure-ground reversal as a function of visual satiation. Journal of Experimental Psychology, 1950, 40, 682-688.

HOLLINGWORTH. H. L. Perceptual fluctuation as a fatigue index Journal of Experimental Psychology, 1939, 24, 511-529.

HOWARD, 1. P. An investigation of a satiation process in the reversible perspective of revolving skeletal shapes. Quarterly Journal of Experimental Psychology, 1961, 13, 19-33.

JACKSON, D. N. Intelligence and reversals of perspective. American Journal of Psychology, 1956, 69, 482-484.

JOHNSON, W. B. Euphoric and depressed moods in normal subjects. Character \& Personality, 1937, 6, 80-98.

JONES, M. B. Authoritarianism and intolerance of fluctuation. Journal of Abnormal Social Psychology, 1955, 50, 125-126.

KÖHLER, W. Dynamics in psychology. New York: Liveright, 1940.

McDougall, W. Physiological factors of the attention process. IV Mind. 1906, 15, 329-359.

MULL, H. K.. ARMSTRONG, G., \& TELFER, B. The effect of brightness upon reversible perspectives and retinal rivalry. American Journal of Psychology, 1956, 69, 123-125.
MULL, H. K., ARP, K., \& CARLIN, P. Indications of a central factor in the uncontrolled and controlled shifts in cube perception. American Journal of Psychology, 1952, 65, 89-90.

MULL, H. K., ORD, N., \& LOCKE, N. The effect of two brightness factors upon the rate of fluctuation of reversible perspectives. American Journal of Psychology, 1954, 67, 341-342.

NECKER, L. A. Observations on some remarkable phenomena seen in Switzerland; and an optical phenomenon which occurs on viewing of a crystal or geometrical solid. Philos. Mag., 1832, (Ser. 1), 3, 329-337.

NEWBIGGING, P. L. The relationship between rate of reversal of figures of reversible perspective and empathy. Canadian Journal of Psychology, 1953, 7, 172-176.

OLSON, R., \& ORBACH, J. Reversibility of the Necker Cube: VIII. Parts of the figure contributing to the perception of reversals. Perceptual \& Motor Skills. 1966, 22, 623-629.

ORBACH, J., EHRLICH, D., \& HEATH, H. A. Reversibility of the Necker Cube: I. An examination of the concept of "satiation of orientation." Perceptual \& Motor Skills, 1963, 17, 439-458.

ORBACH, J., EHRLICH, D., \& VAINSTEIN, E. Reversibility of the Necker Cube: III. Effect of interpolation on reversal rate of the cube presented repetitively. Perceptual \& Motor Skills, 1963, 17, 571-582.

ORBACH, J., \& ZUCKER, E. Reversibility. of the Necker Cube: V. Effect of movement of the figure on the perception of reversals. Perceptual \& Motor Skills, 1964, 18, 945.951.

ORBACH, J., ZUCKER, E., \& OLSON, R. Reversibility of the Necker Cube: VII. Reversal rate as a function of figure-on and figure-off durations. Perceptual \& Motor Skills, 1966, 22, 615-618.

PORTER, E. H. Factors in the fluctuation of fifteen ambiguous phenomena. Psychological Record, 1938, 2, 231-253.

PRICE, J. R. Perspective duration of a plane reversible figure. Psychonomic Science, 1967a, 9, 623-624.

PRICE, J. R. Two components of reversal rate for a rotating skeletal cube: "Conditioned satiation." Australian Joumal of Psychology, $1967 \mathrm{~b}, 19,261-270$

PRICE, J. R. Studies of reversible figures. Unpublished doctoral thesis, University of Western Australia, 1968.

SANTOS, J. F., FARROW, B., \& SOLLEY, C. M. Exposure frequency and the perception of a reversible figure. Perceptual \& Motor Skills, 1962, 14, 199-209.

SHOPLAND, C. D., \& GREGORY, R. L. The effect of touch on a visually ambiguous three-dimensional figure. Quarterly Journal of Experimental Psychology, 1964, 16, 66-70.

SOLLEY, C. M., \& LONG, J. Perceptual learning versus response set learning. Perceptual \& Motor Skills, 1958, 8, 235-240.

SOLLEY, C. M., \& SANTOS, J. F. Perceptual learning with partial verbal reinforcement. Perceptual \& Motor Skills, 1958, 8, 183-193.

SPITZ, H. H. Some experiments with a stationary and revolving three-dimensional skeletal cube. Paper presented at the meeting of the Eastem Psychological Association, New York City, April, 1963.

SPITZ, H. H. The effect of a single monocular depth cue deficit on retardate's perception of the rotating cube illusion. American Journal of Mental Deficiency, 1965, 69, 703-711.

SPITZ, H. H., \& LIPMAN, R. S. Some factors affecting Necker Cube reversal rate. Perceptual \& Motor Skills, 1962, 15, 611-625.

SPIVACK, G., \& LEVINE, M. Spiral aftereffect and measures of satiation in brain-injured and normal subjects. Journal of Personality, 1959, 27, 211-227.

THETFORD, P. E. Influence of massing and spacing on Necker Cube reversals. Perceptual \& Motor Skills, 1963, 16, 215-222.

TITCHENER, E. B. Experimental psychology. New York: MacMillan, 1901.

TORII, S. Figure-ground reversals under successively repeated observations. Japanese Psychological Research, 1960, 9, 25-37.

TUSSING, L. Perceptual fluctuations of illusions as a possible physical fatigue index. Journal of Experimental Psychology, 1941, 29, 85-88.

ULRICH, P., \& AMMONS, R. B. Voluntary control over perceived dimensionality (perspective) of three-dimensional object. Proceedings of the Montana Academy of Science, 1959, 19, 169-173.

VERNON, M. D. Psychology of perception. Harmondsworth: Penguin, 1962.

VICHOLSHOVSKA, A, Illusions of reversible perspective. Psychological Review, 1906, 13, 276-290.

WASHBURN, M. F., MALLAY, H., \& NAYLOR, A. The influence of the size of an outline cube on the fluctuations of its perspective. American Journal of Psychology, 1931, 43, 484-489. 